\title{
A Survey of Fungal Contamination Associated with Barberry (Berberis spp.) in Iran
}

\author{
Mehdi Jahani $^{1}$, Ommolbanin Motamed Rezaei ${ }^{2}$, Maryam Khodadadi ${ }^{2}$, Efat Alemzadeh ${ }^{{ }^{*}}$ \\ ${ }^{1}$ Department of Plant Pathology, Faculty of Agriculture, University of Birjand, Birjand, Iran; ${ }^{2}$ Faculty of Public Health, Birjand \\ university of Medical Sciences, Birjand, Iran. \\ Email: *ealemzadeh@yahoo.com
}

Received April 17 ${ }^{\text {th }}$ 2013; revised May 18 ${ }^{\text {th }}, 2013$; accepted June $17^{\text {th }}, 2013$

Copyright (C) 2013 M. Jahani et al. This is an open access article distributed under the Creative Commons Attribution License, which permits unrestricted use, distribution, and reproduction in any medium, provided the original work is properly cited.

\begin{abstract}
Seedless barberry (Berberis vulgaris L. var. asperma) is one of the few unique crops grown only in Iran and southkhorasan. Barberry is a well known medicinal plant in Iran and has been widely used as food additive. The comprehensive survey of fungal contamination of barberry was undertaken in the market of Birjand, during March to June at 2012. Fungal infections of barberry were studied in thirty samples. Among these, Aspergillus spp., Penicillium spp. and Mucor spp. were major contaminants also the results showed that $57 \%$ of barberry was infected and most fungal species related to Aspergillus spp. and penicillium spp. Therefore it needs to undertake the management practices.
\end{abstract}

Keywords: Aspergillus spp.; Barberry; Fungal Contamination; Penicillium spp.

\section{Introduction}

Barberry, as a medicinal plant, has been known and used for a long time in Iran and many other ancient civilizations around the world [1]. This plant belongs to the Berberidaceae family which contains approximately 15 genera and 650 species found in temperate regions of the northern hemisphere. Seedless barberry (Berberis vulgaris L. var. asperma) is one of the few unique crops grown only in Iran and southkhorasan [2]. Due to salinity of water and soil, large cultivated areas in the eastern parts $\left(32.5^{\circ}-34.5^{\circ} \mathrm{N}\right.$. Latitude) of Iran are not suitable for the growth of most crops; hence, in such areas especially during the last 20 years, the seedless barberry has been introduced as a major crop [3].

Barberry (Berberis vulgaris) is a well known medicinal plant in Iran and has been widely used as food additive, also it used to be cultivated for the fruit, which was picked and used for garnishing dishes and medicinal purpose. In southwestern Asia, especially Iran and in Europe, the berries are used for cooking and for making jam [4].

In Iran more than 5000 tones of barberries are produced each year. Southkhorasan, located at the northeastern Iran, is the production center with about 6000 hectares of field growing barberry. Each year, more than

${ }^{*}$ Corresponding author.
4500 tones are harvested in Southkhorasan region alone. Barberry is cultivated in Southkhorasan, especially around Birjand and Ghayen where environmental conditions (i.e. hot weather, low relative humidity, water shortage and soil condition) are unfavorable for the growing of other horticultural crops [2]. There is evidence that the barberry was domesticated about 200 years ago in this region. Higher price in the internal markets encouraged growers to establish new orchards of this crop. Cultivation area increased from 704 ha in 1981 to 8082 ha in 2005 and barberry production increased from $941 \mathrm{t}$ to more than $8540 \mathrm{t}$ in recent years. The province of Khorassan with a production of more than $90 \%$ of the total production is the main region of barberry production in Iran [5].

Water and enzyme activities, microbial growth, and change in the pigment color are some of the most important factors that affect the quality of barberry. In other hand, microbial growth such as fungi cause reduces nutrient value of barberry and their quality. Barberry packaging is another problem related to these damaging factors $[3,6]$. In this study we investigate fungal infections in used barberries in distribution system and packaging system.

\section{Materials and Methods}

Thirty samples (50 - 100 g each) of dried fruits of bar- 
berry were collected from shops and markets of different sanitation levels in Iran, Birjand, during March to June at 2012. Each sample was put in a sterile polyethylene bag, sealed and transferred to the laboratory. All barberry samples were immersed in sodium hypochlorite solution (5\%) as a sterilizer, for 3 minutes, rinsed 3 times in sterile distilled water then dried between sterile filter paper.Ten grams of samples were isolated and fungal isolates were isolated from them with using the dilution plate method as described by Johnson and Curl (1972) [7]. Each of the samples was comminuted for $15 \mathrm{~min}$ in $90 \mathrm{ml}$ of sterile Ringer solution. Other dilutions ( 0.01 , 0.001 ) were made and one $\mathrm{ml}$ of per final dilution was placed in each petridish. 15 - $20 \mathrm{ml}$ of DRBC media were added to each petridish. Six plates were used for each specimen with $10 \mathrm{gr}$ weight (2 plates for each dilution). The plates were incubated at $25^{\circ} \mathrm{C}$ for 5 - 7 days. Incubated dishes were checked daily and growing fungi were counted, then subcultured and purified on PDA [8].

Pure isolated fungi were identified according to the most documented keys in fungal identification $[9,10]$. The results were analyzed by spss (Ver. 11.5) software.

\section{Result and Discussion}

Three fungi were isolated from barberry fruits in Iran, Southkhorasan. The fungi include Aspergillus spp., Penicilium spp. and Mucor spp.

In this study, the standard range of the number of colonies grown on dextrose agar medium is less than 1000 . Based on Standard Research Institute of Iran, colony count less than 1000 is to be considered as no infected and more than 1000 as infected. Samples of Barberry in dextrose agar medium at three dilutions of 0.1, 0.001 and 0.001 were cultured, and the results are as follows.

Different levels of fungal contamination are in dextrose agar medium at various dilutions as follows:

Contamination of Aspergillus genus in dilution of 10 is $86.7 \%$ and rate of this fungus in dilutions of 100 and 1000 is $60 \%$ and $33.3 \%$, respectively (Figure 1). This result suggests a reduction in high dilutions. Previous researches conducted also suggest a high percentage of food contamination is due to Aspergillus genus, also these studies have shown that the most of food are infected with fungus, under uncomfortable storage conditions, such as humidity over 70 , temperature in $30^{\circ} \mathrm{C}$.

Contamination of Penicillium genus in dextrose agar medium at dilution of 10 is $90 \%$ and the rate of this fungus in dilutions 100 and 1000 are $80 \%$ and $63.3 \%$, respectively; (Figure 1) that suggests a reduction in high dilution. Results from this study indicate that most fungal contamination in samples of barberry is Penicillium genus.

Contamination of Mucor genus in dextrose agar medium at dilution of 10 is $3.3 \%$ that this rate at dilutions of

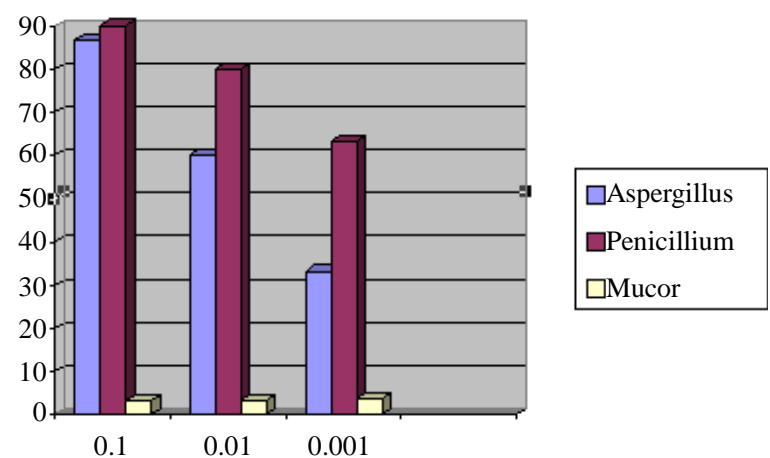

Figure 1. Frequency of aspergillus, penicillium and mucor species in dilutions of $0.1,0.01$ and 0.001 .

100 and 1000 are 3.3\% and 3.7\%, respectively (Figure 1). Contamination rate of Aspergillus and Penicillium samples is $70 \%$ in dextrose agar medium with dilution of 10.

Results of this study showed that Aspergillus and penicillium infect on average $57 \%$ of barberries.

Aspergillus and penicillium fungi product mycotoxin such as Ochratoxin A is a secondary metabolite and has been found in a wide variety of cereal grains, coffee beans, cocoa, beer, red wine and recently in raisins produced in several countries [11]. Similar results on post harvest fungi on storage fruits were reported by Susamma, 2002; Sharma and Mashkorr, 1998. Ghurde and Pachkhede (2010) reported the market and storage diseases of fruits from Amravati.

This survey indicates that contamination rate and also types of fungal infected barberry are important and worrying, especially because mycotoxins are produced by these fungi that are dangerous and some of toxins can be resistant to high temperature. Exposure to consumption of these barberries may be responsible for serious health hazards.

In present study, the fungi like Aspergillus, Penicillium and Mucor species were found on barberry that may cause allergenic effects on human health. Therefore it needs to undertake the management practices.

\section{REFERENCES}

[1] A. Zargari, "Medicinal Plants (in Persian)," Tehran University Press, Tehran, 1990.

[2] A. Tehranifar, "Barberry Growing in Iran,” XXVI International Horticultural Congress: Asian Plants with Unique Horticultural Potential: Genetic Resources, Cultural Practices, and Utilization, ISHS Acta Horticulture, Vol. 1, No. 620, 2003. pp. 193-195.

[3] M. Kafi and A. Balendari, "Berberis: Production and Processing," Language and Literature, Mashhad, 2002, p. 204.

[4] F. Shamsa, A. Ahmadiani and R. Khosrokhavar, "Anti- 
histaminic and Anticholinergic Activity of Barberry Fruit (Berberis vulgaris) in the Guinea-Pig Ileum,” Journal of Ethnopharmacology, Vol. 64, No. 2, 1999, pp. 161-166. doi:10.1016/S0378-8741(98)00122-6

[5] M. Kafi and A. Balandari, "Barberry (Berberis vulgaris): Production and Processing," Ferdowsi University Press, 2004, p. 20 (in Persian).

[6] N. Valipoor, M. T. Motlagh, H. Mosavian, S. A. Mortazavi and A. Tamizi, "Beneficial Effects of Polyethylene Packages Containing Micrometer-Sized Silver Particles on the Quality and Shelf Life of Dried Barberry (Berberis vulgaris)," Journal of Food Science, Vol. 71, 2012, pp. E2-E9. doi:10.1111/j.1750-3841.2011.02497.x

[7] L. F. Johnson and E. A. Curl, "Methods for Research on Ecology of Soil Borne Pathogens,” Burgess Publishing Co., Minneapolis, 1972.

[8] K. B. Raper and D. I. Fennell, “The Genus Aspergillus,” Krieger Publishing Company, New York, 1977.
[9] M. A. Klich, "Identification of Common Aspergillus Species,” CBS Publication, Utrecht, 2002.

[10] H. L. Barnett and B. B. Hunter, "Illustration Genera of Imperfect Fungi,” 4th Edition, American Phytopathological Society Minnesota, 1998.

[11] M. W. Trucksess, J. Giler, K. Young, K. D. White and S. W. Page, "Determination and Survey of Ochratoxin in Wheat, Barley and Coffee-1997," Journal of AOAC International, Vol. 82, No. 1, 1999, pp. 85-89.

[12] P. Susamma, "Fruits Crops Diseases in the Field of Storage,” Kalyani Publishers, New Delhi, 2002.

[13] N. Sharma and A. M. Mashkoor, "Postharvest Diseases of Horticultural Perishables,” International Book Distributing Co., Lucknow, 1998, p. 308.

[14] M. U. Ghurde and A. U. Pachkhede, "The Market and Storage Diseases of Fruits from Amravati (Maharashtra) India,” Bionanofrontier, Vol. 3, No. 2, 2010, pp. 325-327. 